\title{
AIRSA
}

AKSA: JURNAL DESAIN KOMUNIKASI VISUAL

ISSN: 2615-1111 (online)

Available online at:

JURNAL DESAIN KOMUNIKASI VISUAL

http://aksa.stsrdvisi.ac.id

\section{ANALISIS POLA LAYOUT \\ APLIKASI MOBILE COMMERCE POPULER DI INDONESIA DENGAN METODE KUALITATIF HEURISTIK}

\author{
Afif Fais Dzulfikar ${ }^{1}$, Dian Prajarini ${ }^{2}$ \\ ${ }^{1}$ Sekolah Tinggi Seni Rupa dan Desain Visi Indonesia \\ ${ }^{2}$ Sekolah Tinggi Seni Rupa dan Desain Visi Indonesia \\ E-mail: afifdzulfikar58@gmail.com ${ }^{1}$, dianpraja@stsrdvisi.ac.id ${ }^{2}$
}

\begin{tabular}{|c|c|}
\hline ARTICLE INFO & ABSTRAK \\
\hline $\begin{array}{l}\text { Article history: } \\
\text { Received: } 05 \text { April } 2020 \\
\text { Revised: } 13 \text { April } 2020 \\
\text { Accepted: } 16 \text { April } 2020\end{array}$ & $\begin{array}{l}\text { The development of the internet and smartphones, making almost all } \\
\text { activities can be accessed very easily for example shopping online } \\
\text { using a mobile commerce application. In Indonesia, there is much e- } \\
\text { commerce with many users too, but it does not rule out the possibility }\end{array}$ \\
\hline $\begin{array}{l}\text { Keywords: } \\
\text { Heuristic } \\
\text { Design } \\
\text { Layout } \\
\text { UI/UX }\end{array}$ & $\begin{array}{l}\text { to build new e-commerce because Indonesia is the best market for e- } \\
\text { commerce. UI / UX designers are needed to build new mobile } \\
\text { commerce because it requires research on interaction design. UI I } \\
\text { UX layout guidelines needed by designers in the development of } \\
\text { mobile commerce. This study analyzes the layout patterns of mobile } \\
\text { commerce applications in } 4 \text { popular online stores in Indonesia. } \\
\text { This study used qualitative research methods. The analysis is carried } \\
\text { out using the principles of pattern and graphic layout, the heuristic } \\
\text { method of the } 10 \text { Nielsen principles used to evaluate a device or } \\
\text { application. } \\
\text { The results of this study successfully proved that the } 4 \text { Nielsen } \\
\text { principles are used by mobile commerce applications (Bukalapak, } \\
\text { Shopee, Tokedia, Lazada), namely Match between system and the } \\
\text { real world, Consistency and standards, Error prevention, } \\
\text { Recognition rather than recall. The mobile commerce application } \\
\text { has the same shopping flow pattern and interface layout that is like } \\
\text { the navigation buttons on the top and bottom of the page, visual } \\
\text { weight for promotional features, the concept of finger touch for the } \\
\text { safe size of a button measuring } 1 x 1 \text { cm, visual objects entered on the } \\
\text { thumb zone mostly contain elements important and promotions such } \\
\text { as digital bill payments and discounts. }\end{array}$ \\
\hline
\end{tabular}

\section{PENDAHULUAN}

Sejak diadakan Hari Belanja Online Nasional atau Harbolnas pada tahun 2012 pertumbuhan bisnis e-commerce di Indonesia semakin pesat dan konsumenpun juga semakin banyak. Saat ini terdapat sekitar lebih dari 50 e-commerce yang telah memiliki konsumen dan audience besar di Indonesia. E-commerce dengan pengguna terbanyak adalah e-commerce asal 
Indonesia yaitu Tokopedia dan Bukalapak yang kemudian diikuti oleh e-commerce asal luar negeri yaitu Shopee dan Lazada. Saat ini memang sudah banyak e-commerce besar di Indonesia, tetapi peluang untuk membuat atau memulai bisnis e-commerce baru masih terbuka lebar. Menurut Vela Asia, Indonesia merupakan pasar e-commerce yang paling siap di kawasan Asean dengan nilai 135 poin eRI (eCommerce Readiness Index) tahun 2013 menduduki peringkat tertinggi diatas Singapura, berdasarkan kemudahan dalam melakukan bisnis bagi perusahaan $e$ commerce, dilihat dari ketersediaan infrastruktur dan potensi, dengan faktor evaluasi seperti penetrasi internet, nilai transaksi, penggunaan perangkat bergerak, kemudahan pembayaran secara online dan pengiriman. Besarnya peluang pengembangan e-commerce baru, tidak menutup kemungkinan bisnis e-commerce baru dapat bersaing dengan bisnis e-commerce yang sudah besar. E-commerce baru tersebut harus memiliki keunikan atau fokus tersendiri yang dapat menarik konsumen agar dapat bertahan dan bersaing dengan e-commerce yang sudah besar. Namun, untuk memulai bisnis e-commerce baru tidaklah mudah, karena membutuhkan modal dan waktu yang tidak sedikit untuk melakukan riset seperti pada pembuatan platform $e$ commerce itu sendiri, sebagai contoh yaitu untuk menentukan menentukan target audience, keunikan dan lain-lain, karena jika tidak dilakukan riset yang tepat maka e-commerce baru tidak akan dapat bersaing ditengah pasar Indonesia. Kebutuhan platform e-commerce sendiri tidak hanya website, namun juga aplikasi mobile yang justru sangat penting karena kebutuhan kemudahan akses dimana saja dan kapan saja. Kebutuhan kemudahan akses aplikasi mobile tersebut menyebabkan penggunaan platform e-commerce di website dan aplikasi mobile itu menjadi berbeda dalam segi tampilan dan flow.

Tampilan visual yang berbentuk presentation menunjukkan gambaran bahwa tampilan visual dalam penyusunan sebuah website e-learning mempunyai peranan yang cukup besar (Hamzah, dkk., 2014). Komponen desain user interface yang mudah digunakan menurut pengguna dan lebih user-friendly mengindikasikan bahwa (1) komponen desain layout dengan menu utama berbentuk baris tidak memiliki pengaruh yang signifikan terhadap kemudahan penggunaan aplikasi, (2) warna jingga lebih mudah digunakan, (3) komponen desain kontrol yang mudah digunakan oleh pengguna adalah kontrol dengan ikon dan teks penjelas (Ghiffary, dkk., 2018). Pada aplikasi mobile social media, dalam evaluasi UX menunjukkan (1) variabel value, faktor yang paling berpengaruh adalah keberfungsian, (2) variabel adoptability, faktor yang paling berpengaruh adalah kemudahan akses (easy to access), (3) variabel desirability, faktor yang paling berpengaruh adalah desain visual yang inovatif (innovative visual design), (4) 
variabel usability, faktor yang paling berpengaruh adalah kemudahan dipelajari (learnability) (Munthe, dkk., 2018).

Layout dapat dijabarkan sebagai tataletak elemen-elemen desain terhadap suatu bidang dalam media tertentu untuk mendukung konsep/pesan yang dibawanya (Rustan, 2017). Sedangkan elemen visual yang baik dalam desain user interface (McKay, 2013) antara lain layout, tipografi, ikon dan simbol, keterjangkauan, grafis, warna serta animasi dan transisi. Dalam elemen visual aplikasi mobile juga terdapat visual weight yaitu elemen-elemen visual yang dapat menarik perhatian mata, elemen-elemen tersebut adalah warna, ukuran, posisi, tekstur, bentuk, orientasi vertical atau horizontal (Bradley, 2014). Hal-hal yang mendasari pembuatan aplikasi mobile (1) finger touch dengan ukuran aman untuk membuat sebuah elemen interaktif area sentuh jari (finger touch) setidaknya $1 \mathrm{~cm} \times 1 \mathrm{~cm}(0,4$ inci $\times 0,4$ inci) dalam ukuran fisik, diberikan dan diposisikan dengan ruang yang cukup dari target sentuh lain yang berdampingan agar mudah dan akurat digunakan (Harley, 2019); (2) thumb zone yang merupakan zona yang bisa dijangkau oleh ibu jari pengguna saat menggunakan aplikasi; (3) kerangka umum desain interaksi touchscreen pada aplikasi mobile setidaknya membutuhkan 3 konten yakni primer yang berada pada tengah halaman, kemudian sekunder yakni seperti tab navigasi yang berada di atas dan di bawah, kemudian tersier yakni yang lebih baik disembunyikan di dalam menu (Hoober, 2017).

Dalam user experience, analisis heuristic (heuristik) adalah panduan, prinsip umum, atau aturan yang dapat menuntun keputusan rancangan atau digunakan untuk mengkritik suatu keputusan yang sudah diambil. Metode ini melibatkan evaluator untuk memberikan masukan kemudian dikategorikan dalam prinsip-prinsip heuristic (Islam dan Rahayu, 2018). Studi Nielsen mengungkapkan ada 10 prinsip heuristic yang dapat dijadikan panduan desainer dalam membuat sebuah website atau aplikasi (Rahman, 2014) antara lain (1) visibility of system status; (2) match between system and the real world; (3) user control and freedom; (4) consistency and standards; (5) error prevention; (6) recognition rather than recal; (7) flexibility and efficiency of use; (8) aesthetic and minimalist design; (9) help users recognize, diagnose, and recover from errors; (10) Help and documentation.

Tampilan sebuah aplikasi sangat dipengaruhi oleh layout dan tata letak elemen visual karena sebuah aplikasi berbeda dengan media grafis dalam bentuk cetak karena aplikasi berinteraksi dan melakukan timbal balik langsung dengan pengguna, maka layout sangat berperan penting pada aplikasi dibandingkan sebuah elemen grafis. Selain itu, besarnya potensi masalah e-commerce, maka semua pihak yang berkompeten harus mencermatinya sejak dini dan 
membuat aturan main yang jelas sehingga resiko tersebut tidak menjadi kenyataan (Achjari, 2000). Oleh karena itu dibutuhkan suatu tinjauan pada pola layout aplikasi mobile commerce yang memudahkan bagi desainer $U I / U X$ untuk mengetahui elemen visual dan tata letak yang harus diterapkan dalam suatu aplikasi mobile commerce, sehingga konsumen merasakan kemudahan karena terdapat pola yang serupa pada setiap aplikasi mobile commerce dengan menerapkan Evaluasi Heuristik menggunakan Prinsip Nielson.

\section{METODE PENELITIAN ATAU PERANCANGAN}

Metode penelitian yang digunakan adalah metode penelitian kualitatif heuristik karena tujuan penelitian ini bertujuan untuk menemukan sebuah pola layout yang ada di dalam user interface pada aplikasi mobile commerce. Hal ini menunjuk kepada proses pencarian internal, dimana seseorang berusaha untuk memahami hakikat dari pengalaman yang dimaksudkan untuk analisis lebih lanjut sehingga nantinya diperoleh arti yang mendalam (Conny R., 2010). Berdasarkan seluruh prinsip heuristik yang telah dipaparkan, prinsip heuristik yang digunakan penulis untuk meneliti aplikasi mobile commerce adalah Match between system and the real world, Consistency and standard, Error prevention, Recognition rather than recall. Teori mengenai layout yang dipakai adalah mengenai tata letak, objek visual (meliputi foto, warna, artwork atau gambar, frame/kotak). Empat prinsip Nielsen tersebut dicocokkan dengan hasil analisa mengenai layout yang didapat setelah mendapatkan pola alur belanja sesuai dengan batasan penelitian.

Metode pengumpulan data dilakukan dengan cara (1) Wawancara kepada evaluator (Islam dan Rahayu, 2018) yaitu Andika Indrayana, M.Ds. dengan hasil bahwa desain interaksi seperti hubungan antar manusia, poin utama dalam desain interaksi adalah feedback, seperti ketika orang berkomunikasi maka ketika aka nada timbal balik seperti argumen mengenai pernyataan yang diberikan. Pada aplikasi mobile sendiri hal ini seperti ketika sebuah smartphone yang dikunci, kemudian dibuka oleh pengguna menggunakan sandi, maka program dari aplikasi memberikan feedback berupa terbukanya aplikasi tersebut. Desain dan fitur pada e-commerce sekarang ini mempunyai pola yang mirip karena mereka menggunakan metode ATM ( Amati, Tiru, Modifikasi ) seperti ketika salah satu aplikasi memiliki fitur yang meningkatkan traffic atau keuntungan, maka akan ada aplikasi lain yang akan mengadaptasi fitur tersebut dengan menambahkan sedikit inovasi baru sehingga secara tidak langsung mereka seperti bertukar ide dan membentuk kesamaan pola dalam segi desain dan fitur. (2) Dokumentasi atas tampilan- 
tampilan user interface pada 4 aplikasi mobile commerce (Tokopedia, Bukalapak, Shopee dan Lazada) yang berupa screenshot pada smartphone. (3) Studi Literatur referensi berupa jurnal ilmiah, buku, dan website baik teori ataupun metode penelitian yang mempunyai relevansi dengan mobile commerce, user interface, user experience dan pola layout pada aplikasi mobile.

\section{PEMBAHASAN}

\subsection{Deskripsi Data}

Objek penelitian yang akan diteliti penulis adalah 4 mobile commerce terbesar di Indonesia yakni Tokopedia, Bukalapak, Shopee dan Lazada. Sebelum melakukan penelitian, penulis menentukan batasan dengan asumsi bahwa penggunaan platform e-commerce dimulai dengan pengguna sudah mempunyai akun dan sudah login akan membeli sebuah produk yaitu sepatu merek converse dengan metode search atau kolom pencarian, setelah itu pengguna diasumsikan bahwa pengguna memilih dan mengklik produk sepatu converse yang muncul di bagian paling kiri atas dari hasil pencarian. Smartphone yang digunakan adalah merk Asus Zenfone 3 Max (ZC553KL), dengan layar 5,5 inch.

Pada pola alur pembelian dilakukan pengamatan pada 4 (empat) user interface yaitu beranda, halaman pilihan barang, halaman informasi barang, halaman pembayaran (checkout). Halaman beranda keempat mobile commerce, dimana setelah dimunculkan halaman beranda, sesuai asumsi pada kolom pencarian, pengguna akan menemukan bahwa ketika kolom pencarian diklik yang dalam hal ini pengguna belum mengetikkan kata yang ingin dicari maka akan menemukan tampilan yang menunjukkan kata kunci-kata kunci sugesti berdasarkan riwayat pencarian dan pencarian populer sehingga memunculkan.

\subsubsection{Pola Alur Pembelian Barang}

Hasil penelitian menunjukkan bahwa 4 mobile commerce memiliki banyak kesamaan dalam mengarahkan pengguna untuk melakukan pembelian suatu barang, dimulai dari beranda, karena diasumsikan bahwa pengguna sudah memiliki akun dan sudah login, maka pengguna tidak ada peringatan untuk membuat akun baru. Setelah berada di beranda, pengguna melakukan pencarian di kolom pencarian, di sini ada sedikit perbedaan diantara keempat mobile commerce ini yakni ketika pengguna mengklik kolom pencarian muncul sugesti pencarian, di aplikasi Bukalapak dan Shopee (Gambar 1) memunculkan sugesti dalam bentuk tampilan visual, sedangkan Tokopedia dan Lazada hanya berbentuk teks (Gambar 2). 


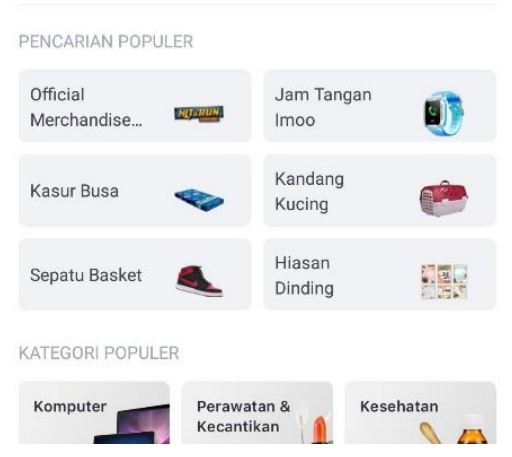

(a) Bukalapak

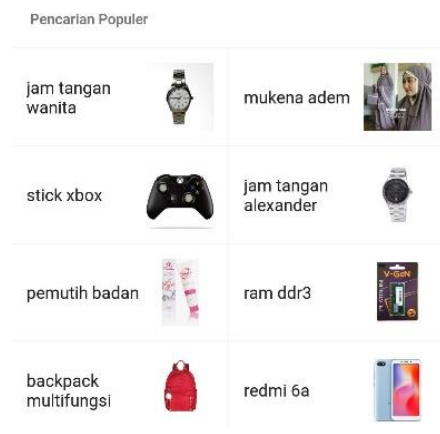

(b) Shopee

Gambar 1. Tampilan Pencarian Populer Bukalapak dan Shopee (Sumber: Dokumentasi Penulis)

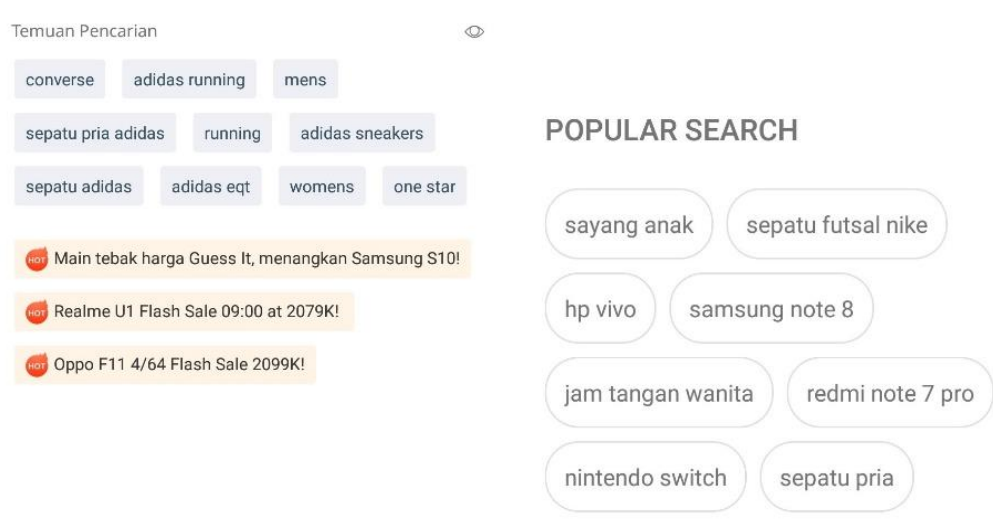

(a) Lazada

(b) Tokopedia

Gambar 2. Tampilan Pencarian Populer Lazada dan Tokopedia (Sumber: Dokumentasi Penulis)

Ketika pengguna sudah memilih dan mengklik barang pilihannya maka akan ditampilkan halaman informasi barang. Langkah berikutnya adalah pengguna melakukan pembelian, pada langkah ini ada sedikit perbedaan diantara keempat mobile commerce tersebut. Hal yang membedakan adalah ketika barang memiliki variasi warna atau ukuran pada barang seperti sepatu, Lazada, Tokopedia dan Shopee memunculkan halaman untuk memilih warna, ukuran dan jumlah yang akan dibeli (Gambar 3). Sedangkan Bukalapak, hanya menyediakan catatan untuk pelapak pada halaman pembayaran. Pemilihan variasi ini menyebabkan adanya percabangan opsi langkah untuk membuat sebuah aplikasi, namun sebenarnya ketika halaman ini muncul terdapat sebuah kelebihan yakni ketika pengguna lupa memilih variasi barang, maka tidak akan terjadi kesalahan dalam pengiriman nantinya karena sudah otomatis secara tidak langsung diingatkan oleh sistem aplikasi, hal ini sesuai dengan salah satu dari 10 prinsip Nielsen yakni "Recognition 
rather than recall" karena meminimalkan pengguna untuk mengingat apakah pesanannya sudah benar.

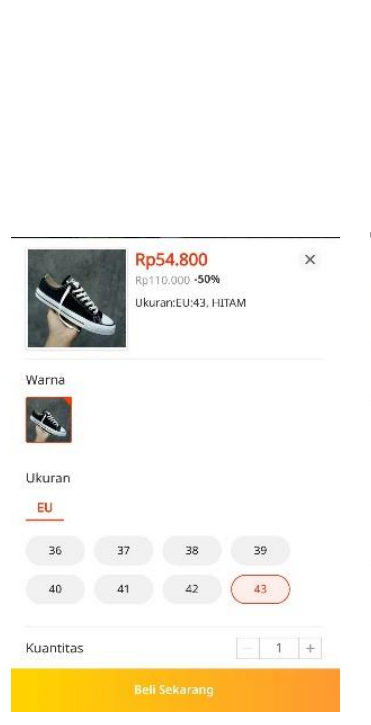

(a) Lazada

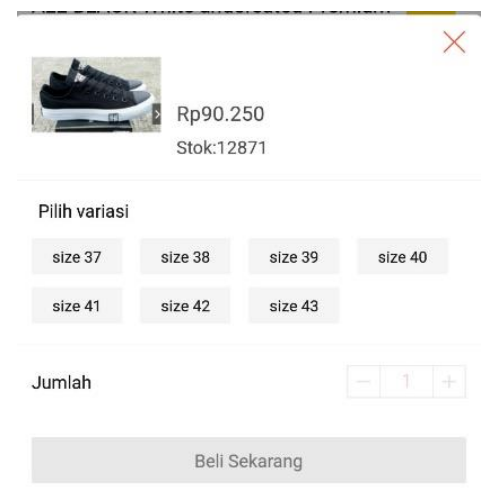

(b) Shopee

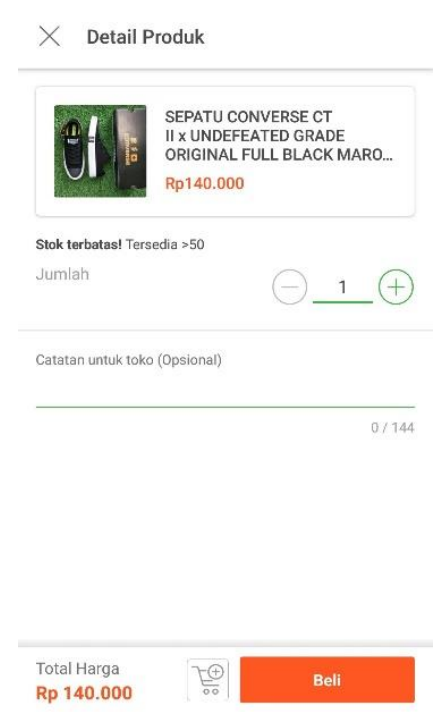

(c) Tokopedia

Gambar 3. Popup Pilihan Variasi Lazada, Shopee dan Tokopedia (Sumber: Dokumentasi Penulis)

Pada proses pembayaran ini ketika pengguna ingin melakukan check out dari halaman keranjang belanja, maka pengguna disajikan pilihan untuk membayar total kesemua harga barang yang telah dibeli, sedangkan untuk sistem yang langsung menuju pilihan tersebut tidak disajikan pilihan untuk membayar kesemuanya, karena jumlah barang yang ditotal otomatis hanya satu barang. Pada halaman pembayaran terkadang juga dibagi ketika pengguna akan melakukan konfirmasi metode pembayaran, jasa pengiriman atau alamat (Gambar 4) pembagian halaman ini biasa disebut bitesize dalam user experience. 


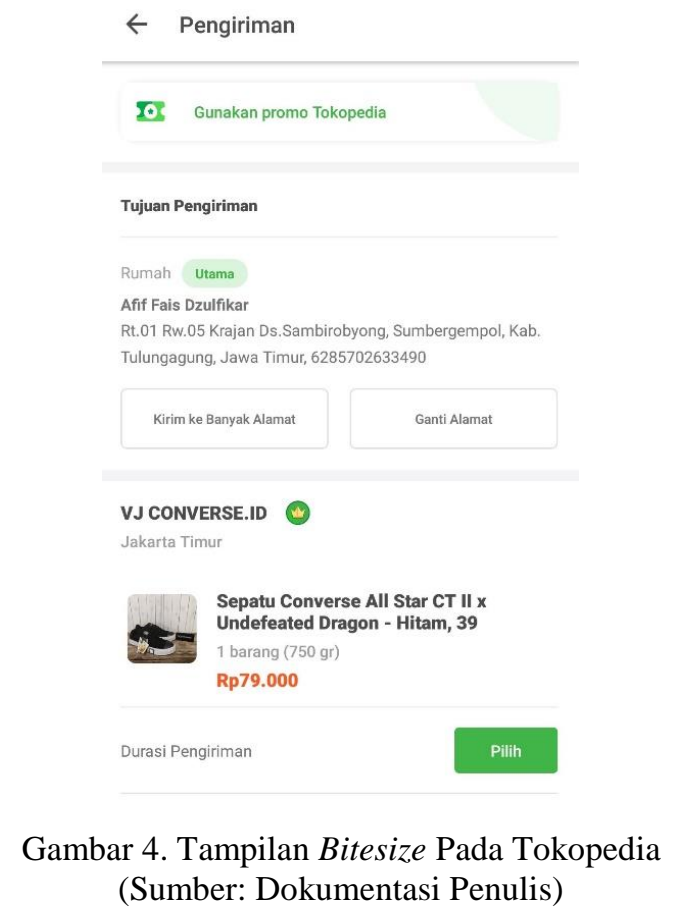

Pada aplikasi Bukalapak, terdapat sebuah perbedaan tersendiri dari keempat aplikasi mobile commerce, yakni ketika pengguna mengklik tombol kembali (pada smartphone) maka otomatis akan muncul popup yang berisi "Keluar dari proses transaksi? Jika kamu keluar dari proses transaksi, transaksi kamu akan dibatalkan" (Gambar 5). Kemudian disajikan pilihan "Tidak" dan “уа", рорир ini berfungsi untuk memberi peringatan pada pengguna ketika pengguna tidak sengaja mengklik tombol kembali (pada smartphone) sehingga pekerjaan yang sudah dilakukan pada halaman pembayaran tidak langsung hilang dan diulang kembali dari awal, popup ini juga merupakan representasi dari salah satu dari 10 prinsip Nielsen yakni "Error prevention" Maksudnya yakni lebih baik membuat desain yang mencegah pengguna melakukan kesalahan daripada memunculkan pesan error yang bagus. Pencegahan kesalahan pengguna disini yaitu ketika pengguna tidak sengaja mengklik tombol kembali pada smartphone muncul muncul konfirmasi apakah yakin pengguna akan meninggalkan halaman menggunakan bahasa dengan pendekatan bahasa sehari-hari seperti dengan sebutan "kamu", pemberian saran disini ditampilkan dengan meletakkan tombol "tidak" pada bagian kiri dengan warna yang lebih mencolok, sedangkan tombol "ya" dibagian kanan dengan warna yang hampir sama dengan latar belakang. 


\section{$\times \quad$ Keluar dari Proses Transaksi?}

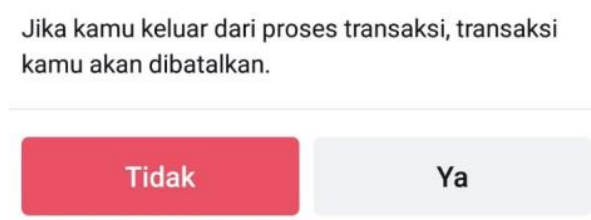

Gambar 5. Tampilan Peringatan Keluar Pada Bukalapak (Sumber: Dokumentasi Penulis)

\subsubsection{Layout User Interface Aplikasi}

Layout user interface pada aplikasi yang akan dibahas adalah meliputi objek visual, penempatan objek visual, warna, tipografi, ikon dan transisi. Pembagian pembahasan layout ini berdasarkan pembagian yang telah disampaikan penulis pada bagian pembahasan pola alur pembelian, maka pada setiap masing-masing bagian halaman akan dibahas mengenai layout.

a. Beranda

Keempat mobile commerce memiliki pola yang sama mengenai objek visual yang muncul pada halaman beranda, mulai dari atas terdapat kolom pencarian, kemudian pasti terdapat elemen visual berbentuk seperti banner hasil olah digital dari foto dan tipografi yang berisi promo utama masing-masing e-commerce yang berbentuk parallax. Efek parallax adalah salah satu efek website atau aplikasi yang berupa objek yang bisa bergeser otomatis sehingga terlihat bergerak ataupun digeser secara manual. Pada beranda keempat aplikasi ini banner berperan sebagai visual weight, banner ini memiliki porsi ukuran yang cukup besar dan mempunyai warna yang cukup dominan diantara elemen visual lain. Sehingga tujuan informasi promo yang disampaikan akan menjadi tersampaikan dengan baik. Selain elemen visual yang berbentuk olahan digital dari foto, elemen visual yang pasti terdapat pada keempat aplikasi yakni ikon. Ikon yang digunakan memiliki 2 kategori, yang pertama yakni ikon yang berada pada top navigation dan bottom navigation tampilan aplikasi, ikon ini memiliki karakter lebih sederhana dan cenderung tidak berwarna atau hanya 2 warna, ikon ini lebih cenderung memiliki fungsi untuk aktifitas yang berhubungan dengan proses belanja seperti untuk cek dompet digital, notifikasi, pesan, keranjang atau troli dan akun.

Kategori kedua yakni ikon yang biasanya terletak di tengah halaman atau dibawah banner promo utama, ikon ini memiliki warna yang lebih kompleks dan terkadang memiliki efek seperti glowing atau bersinar, fungsi elemen ini lebih cenderung untuk aktifitas seperti promo, voucher, pintasan pembayaran online, games dan lain-lain. Ikon 
pada top dan bottom navigation sebenarnya merupakan tombol-tombol yang digunakan untuk mengarahkan pengguna ke halaman lain agar lebih cepat. Letak tombol ini cukup berdekatan, sehingga menuntut untuk menggunakan ukuran tombol yang tepat agar pengguna tidak melakukan kesalahan ketika mengklik tombol. Tombol yang digunakan berukuran $1 \mathrm{~cm}$ x $1 \mathrm{~cm}$ sesuai dengan teori yang dikemukakan oleh Harley (Harley, 2019). Elemen visual yang Sudah menjadi pola adalah berupa foto barang baik itu berupa flashsale, ataupun produk terlaris. Format foto barang ini sama seperti pada halaman pilihan barang yakni terdapat harga dan nama barang, terkadang ketika barang tersebut berupa barang flashsale maka terdapat keterangan berupa jumlah barang yang sudah terjual dibawah foto.

Letak obyek visual pada keempat mobile commerce di bagian beranda memiliki kesamaan yang digunakan untuk melakukan aktifitas instan diantaranya yakni kolom pencarian, posisi kolom pencarian berada diatas agar ketika pengguna ingin melakukan pencarian suatu barang yang sudah ditentukan, dapat dilakukan secara cepat. Pada aplikasi Bukalapak dan Shopee, ikon keranjang atau troli terdapat pada bagian atas, sedangkan Tokopedia dan Lazada terdapat pada bagian bottom navigation. Sudah cukup tepat untuk meletakkan fotot barang yang berformat seperti ini pada beranda karena selain ditujukan untuk aktifitas cepat, beranda juga merupakan bagian yang cocok untuk mensugesti pengguna agar berbelanja barang yang sedang promo atau flashsale. Tata letak khususnya pada aplikasi mobile sangat dipengaruhi oleh kenyamanan pengguna, hal ini berhubungan dengan thumb zone yang mana kebanyakan orang memakai ibu jarinya untuk mengoperasikan smartphone mereka. Pada halaman beranda, elemen visual yang penting dan promo kebanyakan masuk pada thumb zone contohnya seperti ikon tombol seperti pembayaran, flash sale ataupun hot product, selain itu tombol bottom navigation masih masuk zona aman untuk thumbzone sehingga memberi kenyamanan pada pengguna.

Warna pada beranda cenderung sesuai dengan brand masing masing. Pada Lazada dan Tokopedia sebenarnya tetap memakai warna brand pada ikon-ikon dan footernya, akan tetapi pada banner promo utama, kedua e-commerce ini memakai warna yang menyesuaikan dengan warna banner (yang tidak menggunakan warna brand). Sehingga setiap banner berganti maka warna latar belakang banner ini juga ikut menyesuaikan warna banner. Pergantian warna ini akan semakin memperkuat efek parallax yang dipakai karena tidak hanya gerakan saja namun juga warnapun menyesuaikan. 


\section{b. Halaman Pencarian}

Objek visual yang terdapat pada halaman pencarian bertujuan untuk mensugestikan pengguna melalui riwayat pencarian atau pencarian populer. Persamaan yang sudah ditemukan adalah terdapat teks yang merupakan daftar popular search atau pencarian populer dan riwayat pencarian. Untuk format tampilan teks ini ada dua jenis yang pertama yaitu berbentuk mengelompokkan kata kunci dengan menggunakan kotak seperti pada shopee, sedangkan yang lainnya adalah dengan daftar urutan. Pada teks pencarian populer keempat aplikasi mobile commerce lebih cenderung menggunakan pengelompokkan kotak-kotak kata kunci, bahkan pada aplikasi Shopee dan Bukalapak teks yang disajikan pada daftar pencarian populer dicantumkan dengan foto produk.

Tata letak objek visual yang sudah menjadi pola pada keempat aplikasi mobile commerce adalah kolom pencarian yang tetap berada diatas dan ketika kolom pencarian diklik, maka dibawah kolom pencarian akan terdapat sugesti dari riwayat pencarian karena hal ini sesuai dengan salah satu teori Nielsen yaitu "Recognition rather than recall" yakni untuk memudahkan ketika pengguna ingin mencari barang yang sudah pernah dicari sebelumnya sehingga tidak perlu susah untuk mengingat-ingat kembali. Sugesti lainnya yaitu mengenai pencarian populer yang terletak dibawah sugesti riwayat pencarian, peletakkan kedua sugesti ini diurutkan berdasarkan prioritas mana yang lebih dekat dengan pengguna yang pertama yakni barang yang pernah dicari dan kedua yaitu barang yang populer. Jadi hal ini dapat menambah kekuatan personal pada aplikasi mobile. Warna brand pada halaman pencarian tidak terlalu dimunculkan karena halaman ini ditujukan agar pengguna bias fokus dengan teks dan lebih berkaitan pada barang yang dicari bukan untuk memikat pengguna sepeti pada halaman beranda.

\section{c. Halaman Pilihan Barang}

Objek Visual yang terdapat pada halaman ini yakni yang sudah pasti adalah kolom pencarian dan header lain seperti keranjang. Selain elemen header yang sebelumnya ada diberanda, disamping kiri kolom pencarian terdapat tombol kembali. Di bawah kolom pencarian terdapat pembagian barang menurut kategori masing-masing e-commerce, akan tetapi keeempat aplikasi mobile commerce semua memiliki kesamaan yakni pasti membagi dengan beberapa kategori seperti pembagian dari keterkaitan dengan pencarian, harga, toko, mall dan lain-lain. Selain mengkategorikan barang, setiap mobile commerce pasti memberikan fitur sortir baik berupa ikon, ataupun tulisan. Ikon sortir biasanya berbentuk corong kerucut. 
Tata letak objek visual pada halaman pilihan barang keempat mobile commerce memiliki kesamaan yakni di atas ditampilkan kolom search dan disebelah kirinya terdapat tombol kembali, kemudian disebelah kanan terdapat ikon-ikon seperti pada beranda, di bawah kolom pencarian terdapat kata kunci-kata kunci yang berkaitan dengan barang yang dicari peletakan posisi di bawah kolom pencarian bertujuan untuk mensugestikan pengguna jika masih belum menemukan barang yang spesifik, sehingga pengguna lebih mudah untuk mengembangkan kata kunci yang ingin dicari.

Fokus utama halaman pilihan barang adalah untuk menampilkan pilihan barang yang dicari setelah mencari di kolom pencarian, maka peletakan dan tampilan visual default dibuat bertumpuk seperti rak-rak yang ada di toko atau supermarket. Hal ini sesuai dengan salah satu prinsip dari 10 prinsip Nielsen yakni "Match between system and the real world“، Kecenderungan warna pada halaman ini tetap menggunakan warna brand masing-masing untuk tampilan seperti tombol ikon dan lain-lain.

d. Halaman Informasi Barang

Tampilan utama halaman informasi barang adalah foto barang. Format foto ini berbeda dengan tampilan foto pada halaman pilihan barang, foto pada halaman informasi barang berukuran cukup besar dan tanpa frame, format seperti ini berfungsi sebagai agar pengguna lebih mengetahui detail fisik barang yang akan dibeli. Fitur yang digunakan adalah tampilan slide yang bisa digeser ke samping sehingga foto yang diunggah bisa lebih dari satu. Pada bagian atas foto ini biasanya terdapat ikon tambahkan ke keranjang atau troli, pesan, favorit atau whislist dan bagikan. Pola objek visual lainnya adalah pada bagian bawah setelah foto, dicantumkan keterangan berupa teks berisi harga, nama barang, rating barang, informasi produk (merk, tipe dan lain-lain), deskripsi barang (yang biss diedit oleh penjual), serta review pembeli mengenai barang tersebut. Review pembeli ini berformat seperti pada komentar seperti pada media sosial namun berisi ulasan mengenai barang, selain itu biasanya terdapat ikon bintang untuk menilai kepuasan mengenai barang.

Bottom navigation tombol menampilkan tombol beli yang berupa teks, kemudian tombol tambahkan ke keranjang, untuk tombol tambahkan ke keranjang berbeda-beda, ada yang memakai ikon troli, dan ada yang memakai teks. Pada bottom navigation ini selain tombol tambahkan keranjang dan tombol beli, keempat aplikasi mobile commerce juga menampilkan tombol chat ke penjual berupa ikon. Untuk tombol tambahkan ke keranjang pada halaman ini sebenarnya terdapat dua tombol, yang pertama berada di 
atas dan yang kedua berada di bagian bottom navigation, kedua tombol yang sama ini bertujuan untuk memanjakan pengguna, ketika pengguna ingin berbelanja secara cepat dan hanya ingin melihat tampilan visual maka pengguna akan memasukkan ke keranjang belanja dengan mengklik ikon atau tombol yang berada di atas. Namun ketika pengguna ingin membaca secara detail dan membandingkan barang terlebih dahulu maka akan mengklik tombol tambahkan ke keranjang di bagian bawah.

e. Halaman Keranjang Belanja

Halaman keranjang belanja berfokus pada daftar barang yang akan dibeli, maka tampilan visual yang disajikan berformat daftar barang yang berupa foto, yang diikuti sedikit informasi mengenai harga, jumlah barang dan variasi. Fungsi daftar pada halaman ini adalah untuk mengecek kembali apakah barang yang akan dibeli (jika lebih dari satu) sudah benar, maka terdapat fitur ceklist berupa ikon centang dan juga fitur hapus yang berupa ikon tempat sampah jika pengguna ingin merubah atau mensortir barang yang akan dibeli. Selain daftar barang halaman ini memunculkan kolom untuk mengisi voucher yang disediakan oleh masing-masing e-commerce. Pada bagian bawah berbeda dengan halaman sebelumnya karena halaman ini merupakan halaman terakhir sebelum pembayaran, maka tombol yang ditampilkan hanya tombol pembayaran atau checkout.

Tata letak objek visual pada halaman ini berformat daftar barang yang mengurutkan mulai dari barang yang pertama kali diklik masukkan keranjang. Pada masing-masing barang teks paling atas adalah nama toko, teks ini memudahkan pengguna jika memiliki barang yang sama namun dengan toko yang berbeda, sehingga memudahkan pengguna untuk membedakan dan membandingkan barang yang akan dibeli.

Pada bagian bawah hanya terdapat tombol bayar atau checkout yang terletak dibagian kanan, posisi ini ditujukan karena ini merupakan langkah terakhir ketika membeli barang sebelum halaman pembayaran dalam mobile commerce sehingga tombol yang tersedia hanya ada satu dan berposisi dikanan mengisyaratkan agar melanjutkan ke langkah berikutnya

\section{f. Halaman Pembayaran/ Checkout}

Objek visual yang dimunculkan pada halaman ini adalah informasi mengenai daftar belanja yang sudah ditentukan dari halaman keranjang belanja, berbeda dengan keranjang belanja, informasi yang disajikan disini lebih mengenai pengecekan kembali seperti alamat dan metode pembayaran yang akan dipilih, sedangkan informasi 
mengenai barang tidak terlalu detail dan hanya berupa daftar. Untuk pemilihan metode pembayaran, disajikan dengan tanda panah guna mengisyaratkan ketika pengguna dapat memilih dengan menggunakan tombol ini (langkah pemilihan selanjutnya). Pada bagian bawah halaman hanya terdapat tombol buat pesanan atau bayar, karena proses ini merupakan yang terakhir pada aplikasi ini (proses pembelian), setelah itu pengguna akan membayar melalui metode pembayaran yang dipilih.

Konfirmasi alamat terletak pada bagian atas halaman karena informasi ini merupakan informasi yang sangat penting dalam proses pengiriman barang nantinya sehingga harus menjadi prioritas, sedangkan untuk konfirmasi metode pembayaran berada di bagian bawah daftar barang karena metode pembayaran merupakan langkah terakhir sebelum mengklik tombol bayar atau buat pesanan yang berada di posisi paling bawah.

Pada halaman ini aplikasi Bukalapak cukup baik menerapkan salah satu prinsip Nielsen yaitu "Error prevention" ketika pengguna tidak sengaja mengklik tombol kembali pada smartphone maka aplikasi otomatis memberi peringatan agar pengguna tidak langsung membuat kesalahan, dengan bahasa yang cukup familiar dengan pengguna, sehingga mendapatkan kesan personal dengan pengguna, selain itu warna yang dipakai juga cukup menonjol pada bagian tombol "tidak" sehingga pengguna lebih disugestikan untuk tidak meninggalkan halaman.

\subsection{Pembahasan}

Ada beberapa poin yang dapat disimpulkan dari pembahasan ini, yakni:

1. Terdapat 6 langkah (halaman utama) untuk melakukan sebuah pembelian dengan catatan pembeli mencari di kolom pencarian.

2. Alur yang digunakan kebanyakan sama, akan tetapi terkadang ada yang ditambah seperti detail variasi dijadikan seperti halaman tersendiri guna meningkatkan fungsi dan mengurangi kesalahan pengguna.

3. Tombol yang baik pada navigasi adalah $1 \times 1 \mathrm{~cm}$

4. Tata letak tombol terkadang mempunyai perbedaan karena mereka menyesuaikan dengan karakter pengguna masing-masing.

5. Empat mobile e-commerce ini memiliki pola dan fitur yang hampir sama karena saling mengadaptasi dari kenyamanan pengguna. 
Evaluasi Heuristik yang dilakukan dengan menggunakan Prinsip Nielsen pada Lazada, Tokopedia, Shopee dan Bukalapak disimpulkan bahwa keempat mobile commerce tersebut sudah memenuhi beberapa Prinsip Nielsen seperti terlihat pada Tabel 1.

\begin{tabular}{|c|c|c|c|}
\hline No & Penerapan Pada Aplikasi & E-commerce & $\begin{array}{l}\text { Teori/Prinsip } \\
\text { Nielsen }\end{array}$ \\
\hline 1. & $\begin{array}{l}\text { Halaman atau pop up pilihan variasi } \\
\text { seperti warna dan ukurnan barang } \\
\text { muncul pada halaman informasi barang. }\end{array}$ & $\begin{array}{l}\text { Lazada, Tokopedia dan } \\
\text { Shopee }\end{array}$ & $\begin{array}{l}\text { Recognition rather } \\
\text { than recall }\end{array}$ \\
\hline 2. & $\begin{array}{l}\text { Pop up peringatan "Keluar dari proses } \\
\text { transaksi?" ketika menekan tombol } \\
\text { kembali smartphone di halaman } \\
\text { pembayaran }\end{array}$ & Bukalapak & Error prevention \\
\hline 3. & $\begin{array}{l}\text { Sugesti dari riwayat pencarian pada } \\
\text { kolom pencarian }\end{array}$ & $\begin{array}{l}\text { Lazada, Tokopedia, } \\
\text { Bukalapak, dan Shopee }\end{array}$ & $\begin{array}{l}\text { Recognition rather } \\
\text { than recall }\end{array}$ \\
\hline 4. & $\begin{array}{l}\text { Peletakan dan tampilan visual default } \\
\text { dibuat bertumpuk seperti rak-rak yang } \\
\text { ada di toko atau supermarket pada } \\
\text { halaman pilihan barang }\end{array}$ & $\begin{array}{l}\text { Lazada, Tokopedia, } \\
\text { Bukalapak, dan Shopee }\end{array}$ & $\begin{array}{l}\text { Match between system } \\
\text { and the real world }\end{array}$ \\
\hline 5. & $\begin{array}{l}\text { Konsistensi pemberian warna brand } \\
\text { pada setiap halaman }\end{array}$ & $\begin{array}{l}\text { Lazada, Tokopedia, } \\
\text { Bukalapak, dan Shopee }\end{array}$ & $\begin{array}{l}\text { Consistency } \\
\text { standard }\end{array}$ \\
\hline
\end{tabular}

Tabel 1: Temuan Penerapan Prinsip Nielsen

(Sumber: Dokumentasi penulis)

Berdasarkan analisis data yang dilakukan ditemukan pola layout pada Lazada, Tokopedia, Shopee dan Bukalapak seperti terlihat pada Gambar 7. 

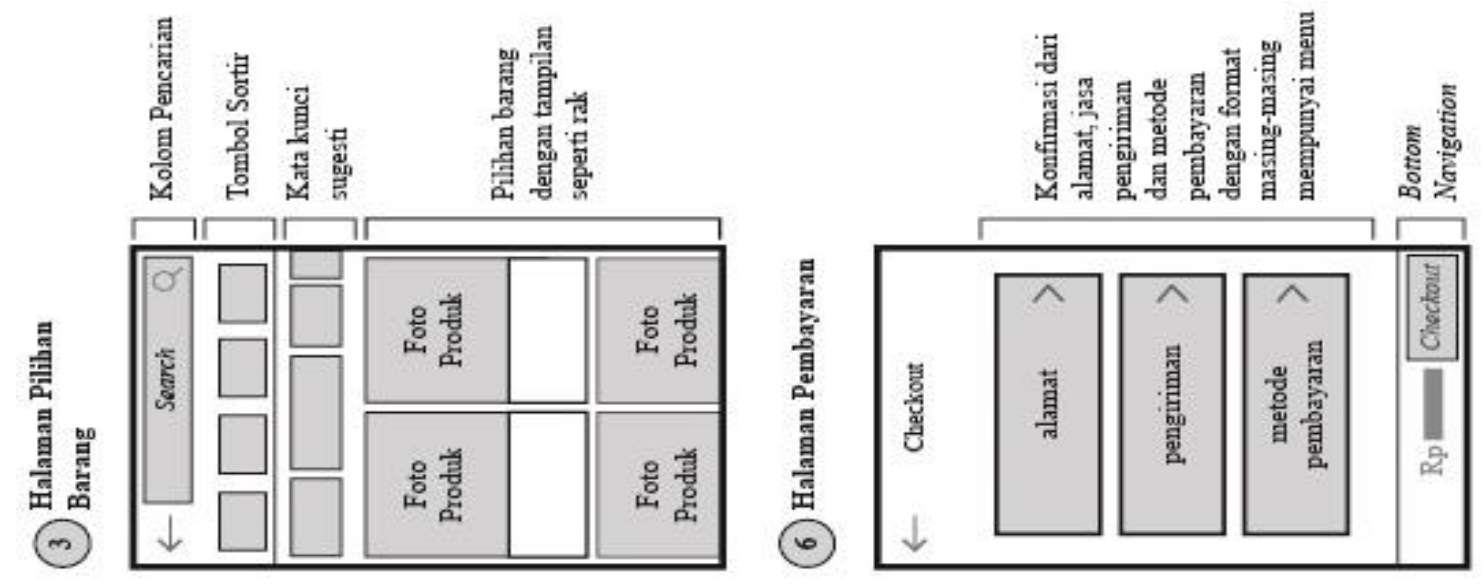

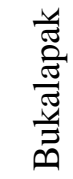
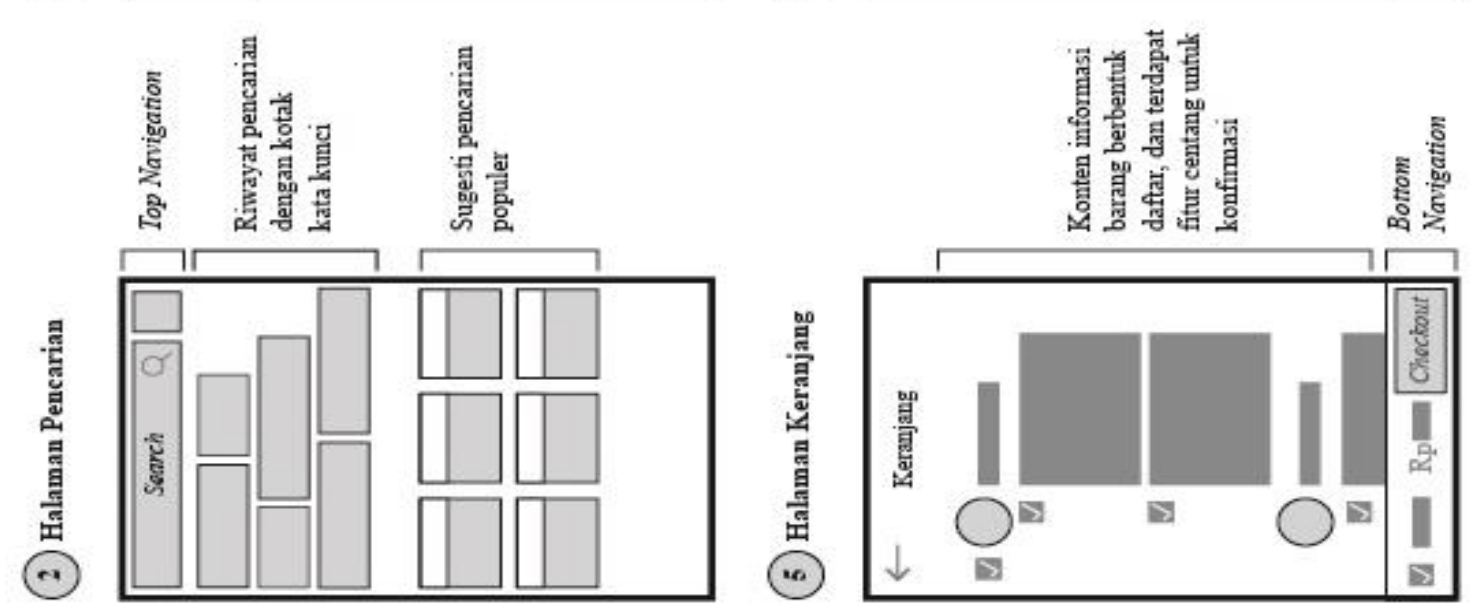

ఫ్
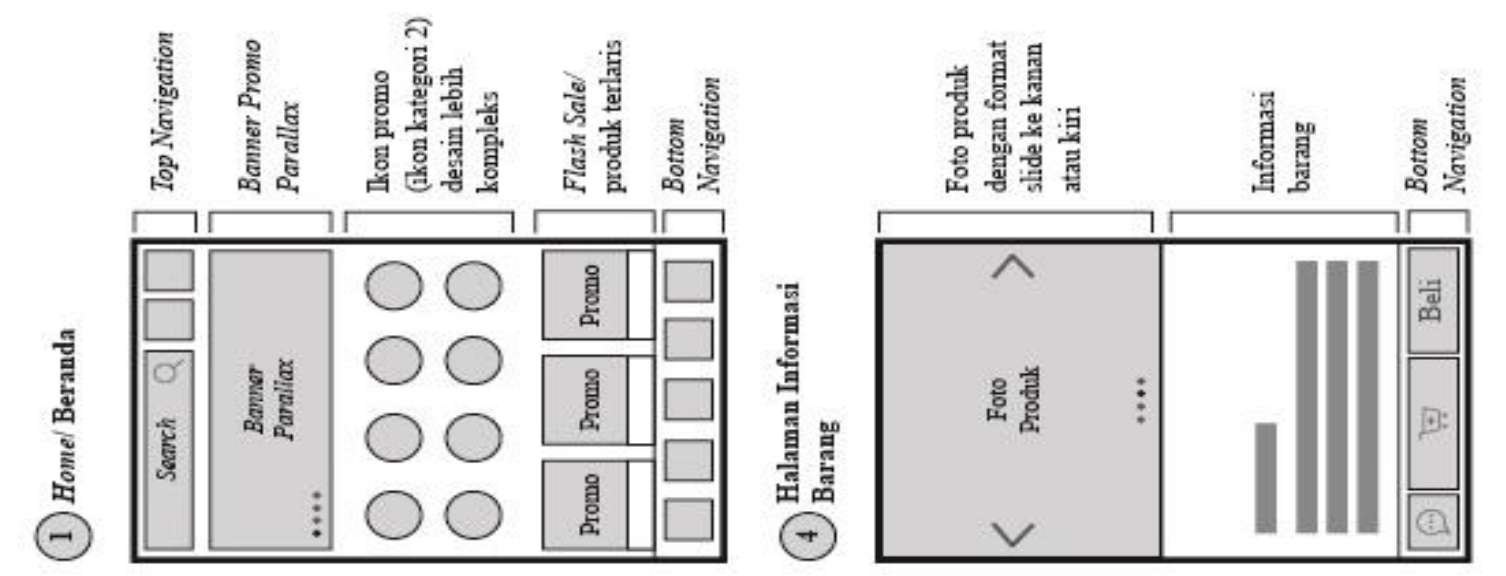

\section{KESIMPULAN}

Berdasarkan hasil penelitian dan pembahasan yang telah diuraikan sebelumnya, penulis dapat menarik kesimpulan bahwa:

1. Empat Aplikasi mobile commerce (Tokopedia, Bukalapak, Lazada dan Shopee) mempunyai kesamaan dari segi layout. Hampir kesemua aplikasi ini memiliki konsep layout yang hampir sama seperti sama-sama memiliki tombol navigasi di atas dan dibawah, terdapat 
visual weight khususnya pada halaman beranda untuk promosi, bahkan hingga fitur-fitur promo pada ikon juga sama, hal ini berguna untuk tujuan memberi kenyamanan pada pengguna ketika pengguna berganti dari aplikasi yang satu dengan yang lain.

2. Pola langkah atau alur pembelian pada 4 aplikasi mobile commerce ini memiliki kesamaan, mulai dari beranda, halaman pencarian, halaman pilihan barang, halaman informasi barang, sampai ke pembayaran.

3. Empat dari sepuluh prinsip Nielsen yang berfungsi untuk mengecek suatu alat atau aplikasi dalam user experience untuk mengetahui tingkat kemudahan dalam penggunaanya (Match between system and the real world, Consistency and standard, Error prevention, Recognition rather than recall.) terbukti dipakai oleh 4 aplikasi mobile commerce ini,

4. Konsep mengenai finger touch untuk ukuran aman suatu tombol terbukti dipakai oleh 4 aplikasi mobile commerce ini, ukuran yang dipakai yakni $1 \mathrm{~cm}$ x $1 \mathrm{~cm}$ terutama pada top dan bottom navigation.

5. Elemen visual yang penting dan promo kebanyakan masuk pada thumb zone (zona ibu jari) contohnya seperti ikon tombol seperti pembayaran, flash sale ataupun hot product, selain itu tombol bottom navigation masih masuk zona aman untuk thumbzone sehingga memberi kenyamanan pada pengguna.

\section{DAFTAR PUSTAKA}

\section{$\underline{\text { Referensi dari buku: }}$}

Conny R., S., 2010. Metode Penelitian Kualitatif. Jakarta: PT. Gramedia Widiasarana Indonesia.

McKay, E. N., 2013. UI is Communication: How to Design Intuitive, User Centered Interfaces by Focusing on Effective Communication. Edited by H. Scherer. Massachusetts: Newnes.

Rustan, S., 2017. Layout Dasar \& Penerapannya. 2017th edn. Jakarta: Gramedia Pustaka Utama.

\section{$\underline{\text { Referensi dari artikel jurnal: }}$}

Achjari, D., 2000. Potensi Manfaat Dan Problem Di E-Commerce. Jurnal Ekonomi dan Bisnis Indonesia, Vol. 15, No. 3. Hal: 388-395.

Ghiffary, M. N. El, Susanto, T. D. and Prabowo, A. H., 2018. Analisis Komponen Desain Layout, Warna, dan Kontrol pada Antarmuka Pengguna Aplikasi Mobile Berdasarkan Kemudahan Penggunaan (Studi Kasus: Aplikasi Olride). Jurnal Teknik ITS, Vol. 7, No. 1. Hal: A143-A148. doi: 10.12962/j23373539.v7i1.28723.

Hamzah, A. A., Syarief, A. and Mustikadara, I. S., 2014. Analisis Kualitatif Tampilan Visual 
Pada Situs E-Learning'. ITB Journal of Visual Art and Design, Vol. 5, No. 2. Hal: 176194. doi: 10.5614/itbj.vad.2013.5.2.6.

Islam, K. and Rahayu, D. A., 2018. Evaluasi Antarmuka Website Tokopedia menggunakan Metode Heuristic. Jurnal ENERGY, Vol. 8, No. 1. Hal: 33-38

Munthe, R. D., Brata, K. C. and Fanani, L., 2018. Analisis User Experience Aplikasi Mobile Facebook (Studi Kasus pada Mahasiswa Universitas Brawijaya). Jurnal Pengembangan Teknologi Informasi dan Ilmu Komputer, 2(7). Hal: 2679-2688.

\section{$\underline{\text { Referensi dari website: }}$}

Bradley, S., 2014. Design Principles: Visual Weight And Direction, Smashing Magazine [Online] (Updated $\quad 14 \quad$ Dec 2014) URL: https://www.smashingmagazine.com/2014/12/design-principles-visual-weight-direction. Diakses pada 12 July 2019).

Harley, A., 2019. Touch Targets on Touchscreens, nngroup.com. [Online] (Updated 5 May 2019) URL: https://www.nngroup.com/articles/touch-target-size. Diakses pada 12 July 2019.

Hoober, S., 2017. Design for Fingers, Touch, and People, UX Matters. [Online] (Updated 6 Mar 2017) URL: https://www.uxmatters.com/mt/archives/2017/03/design-for-fingers-touchand-people-part-1.php. Diakses pada 12 July 2019.

Rahman, T. N., 2014. Nielsen's 10 Usability Heuristics. [Online] (Updated 24 Jul 2014) URL: https://uniteux.com/blog/nielsens-10-usability-heuristics. Diakses pada 17 May 2019. 